Sharif University of Technology
Scientia Iranica
SCIENTIA
IRAN ICAA
http://scientiairanica.sharif.edu

\title{
Cracking effects on chloride diffusion and corrosion initiation in RC structures via finite element simulation
}

\author{
M. Ghanooni-Bagha ${ }^{a, *}$ M.A. Shayanfar ${ }^{b}$, and S.M.H. Farnia ${ }^{c}$ \\ a. Department of Civil Engineering, East Tehran Branch, Islamic Azad University, Tehran, P.O. Box 18735-136, Iran. \\ b. The Centre of Excellence for Fundamental Studies in Structural Engineering, Iran University of Science and Technology, Tehran, \\ P.O. Box 16765-163, Iran. \\ c. School of Civil Engineering, Iran University of Science and Technology, Tehran, P.O. Box 16765-163, Iran.
}

Received 1 April 2018; received in revised form 2 November 2018; accepted 13 November 2018

\section{KEYWORDS \\ Reinforced concrete; \\ Crack width; \\ Crack depth; \\ Chloride ingress; \\ COMSOL \\ multiphysics.}

\begin{abstract}
Chloride ion ingress into concrete causes steel corrosion over time, thereby ending the service life of structures. Sometimes, it severely reduces the loading capacity of reinforced concrete and may even cause the sudden destruction of concrete structures. Concrete cracking stems from different factors, such as shrinkage and tensile stress due to thermal loading and under loading. Modeling and estimating chloride ion ingress into cracked concrete over different periods can facilitate the appropriate determination of structural lifetime and maintenance of reinforced concrete structures. Accordingly, this research investigated the effects of the width and depth of concrete cracks on the rate of chloride ion diffusion and rebar corrosion. To this end, different concrete specimens characterized by various cracking conditions were modeled in COMSOL multiphysics. Analytical results showed that the critical crack that reflected the highest extent of chloride ingress into a specific region at different times was not necessarily the defect with the largest thickness and depth. This finding highlights the importance of investigating crack behavior in the appropriate estimation of structural service life. Nevertheless, over time, considerably wide and deep cracks may ultimately be a reflection of the substantial rate of ingress.

(C) 2020 Sharif University of Technology. All rights reserved.
\end{abstract}

\section{Introduction}

Rebar corrosion is the most important factor in the damage and destruction of reinforced concrete structures [1]. Ignoring its possibility and progress may lead to the obsolescence of these structures and the considerable wastage of investments in construction and maintenance $[2,3]$. Corrosion can threaten the performance of reinforced concrete, even in the early life of the material $[4,5]$. Over time, chloride ion

\footnotetext{
*. Corresponding author.

E-mail addresses: ghanoonibagha@iauet.ac.ir ( $M$.

Ghanooni-Bagha); Shayanfar@iust.ac.ir (M.A. Shayanfar); smhfarnia@gmail.com (S.M.H. Farnia)
}

doi: $10.24200 /$ sci. 2018.50496 .1725 ingress or carbonation increases; in conjunction with high humidity, these processes enable reactions to occur between oxygen and moisture, thereby causing rusting in rebars and increasing the volume of steel [6,7]. The resultant corrosion reduces and increases the area and volume of steel, respectively; it destroys concrete cover and creates cracking, which reduces the strength of $\mathrm{RC}$ members and ends the service life of structures [8,9]. Cracks create many paths for the ingress of destructive elements into concrete and, thus, threaten the durability of concrete [10,11]. Given the complexity of chloride diffusion into cracked concrete, appropriate estimation of the occurrence of this process in reinforced concrete is a critical issue [12].

Many researchers have studied the effects of corrosion and chloride diffusion on intact concrete blocks [13-15]. In an experimental research, Aldea et 
al. tested rapid chloride diffusion into concrete discs subjected to loading and tensile cracks with a thickness of 0.05 to $0.4 \mathrm{~mm}$ [16]. The authors found that chloride ingress is less sensitive to cracks in concrete specimens with typical resistance to such ingress than that in concrete specimens with high resistance [16]. Conciatori et al. proposed a numerical model called TransChlor on the basis of Fick's second law of diffusion and a finite difference method to simulate chloride ion displacement in concrete [17]. Djerbi et al. used cracked samples to test cracking (splitting tests) and investigate the effects of single cracks on chloride ion penetration [18]. Their experimental results showed that the permeability ratio of cracked segments $\left(D_{c r}\right)$ reflected the lack of concrete materials in the samples. The authors also discovered that permeability merely was dependent on crack size; as crack size increased, permeability rose. For cracks with a width greater than $80 \mu \mathrm{m}$, however, permeability remained constant [18]. Jang et al. examined different types of concrete with cracks that were up to $80 \mu \mathrm{m}$ wide and identified a linear relationship between crack width and crack permeability ratio in concrete characterized by cracks that have a small width. The authors reported that for cracks of small widths, permeability ratio decreased as concrete resistance increased [19]. Wang and Ueda experimented on concrete samples with cracks that were 20 to $600 \mu \mathrm{m}$ wide. The researchers indicated that for a crack width that exceeded the critical level (i.e., $60 \mu \mathrm{m}$ ), the amount of $D_{c r}$ was no longer dependent on crack width [20]. Marsavina et al. tested specimens similar to concrete samples with artificial cracks created through the repeated placement and removal of thin copper sheets in the samples (especially in longterm tests). The authors found that diffusion depth increased with increasing crack depth (thicknesses of the artificial cracks in the experiments were set to 0.2 , 0.3 , and $0.5 \mathrm{~mm}$ ) [21]. The effects of crack width remained undetermined-an issue that the researchers acknowledged as requiring further research [21]. Kato et al. proposed a mathematical model for chloride ion ingress into cracked concrete that could simulate ingress under wet conditions and cyclic wet-dry conditions [22]. The researchers stated that in cracked segments, the width of a crack dominantly influenced the rate of chloride ingress into concrete when the supply of chloride was greater than its consumption [22]. Other researchers such as Otieno et al. (2016) [23,24], Wang et al. (2016) [25], and Leung and Hou (2014) [26] drew valuable conclusions by modeling chloride ion diffusion into cracked concrete.

Despite the insights provided by the studies discussed above, they did not delve into the effects of different crack depths and thicknesses and the extent of concrete cover exposed to chloride diffusion. Addressing these issues can facilitate the appropriate determination of structural lifetime and maintenance of reinforced concrete structures. To address the deficiency in existing research, the present study investigated the simultaneous effects of crack width and depth on the rate of chloride ion ingress into concrete and rebar corrosion in different periods. Such effects were also compared.

\section{Formulating chloride diffusion}

Diffusion refers to the displacement of mass, which leads to the spread of chemical components until they reach a uniform mode as they are displaced over time. These chemical components are combined solutions in a solvent or components in gases such as oxygen in the air. The density of chemical components in fluid differs at initial stages and with the passing of time as well as with the displacement of components. Ultimately, however, a uniform balance in the density of fluid is observed. The simplest definition of diffusion was proposed through Fick's equations, which were formulated by Adolph Fick in 1855. This definition is expressed as follows $[27,28]$ :

1. Molar flux is based on diffusion that depends on the concentration gradient;

2. The rate of concentration changes in one point of space, depending on the second derivation of concentration rather than space.

On the basis of the definition above, the first and second rules of diffusion were defined.

\subsection{First law of Fickean diffusion}

The first law of Fick in the mathematical form is written as follows:

$$
N_{i}=-D_{i} \nabla c_{i} .
$$

For species of $i, N$ is the symbol of molar flux $\left(\mathrm{mol} . \mathrm{m}^{2} / \mathrm{s}\right), D$ is the diffusion coefficient $\left(\mathrm{m}^{2} / \mathrm{s}\right)$, and $c$ is the amount of concentration $\left(\mathrm{mol} / \mathrm{m}^{3}\right)$.

Based on the mass continuity equation, we have:

$$
\frac{\partial c_{i}}{\partial t}+\nabla \cdot N_{i}=0
$$

The second Fick's law directly translates into the following relation:

$$
\frac{\partial c_{i}}{\partial t}=D_{i} \nabla^{2} c_{i}
$$

It is assumed here that coefficient $D$ is constant which is correct for dilute solutions; this assumption is usually used for diffusion inside the solids (such as chloride ion diffusion inside concrete), diffusion of chemical materials into dilute solutions like water or other similar liquid solvents, and diffusion of dilute species inside gas (like diffusing carbon dioxide in the air). 


\subsection{Second law of Fickean diffusion}

Second law of Fick diffusion is a linear equation or dependent variable of chemical species' concentration. Diffusion of each chemical species occurs alone. These two characteristics facilitate the proposed mass displacement systems by the second law of Fick for numerical simulation. When diffusion is modeled, modeling mainly begins with this assumption that all coefficients of diffusion are equal and not dependent on temperature, pressure or similar cases. These simplifications lead to assuring linearity of mass displacement equations in the model area and also facilitate connecting known analytic limits. Dimensional analysis of second Fick's law shows that in diffusion processes, the fundamental relationship between passed time and longitudinal square is where diffusion forms in it. Perceiving this relationship is required for performing exact numerical simulations of the diffusion process. The laws of Fick diffusion have only one parameter for determining the speed of diffusion process and that is diffusion coefficient.

\section{Modeling cracked concrete}

\subsection{Sample dimensions}

The dimensions of the 13 concrete specimens subjected to two-dimensional modeling in this work were $300 \times$ $300 \mathrm{~mm}$. As indicated in the investigation conducted in the present research and various dimensional modeling experiments, $300 \times 300 \mathrm{~mm}$ ensures a good balance between the accuracy of results and the time devoted to analysis.

\subsection{Physical and mechanical characteristics of samples}

All of the concrete specimens were modeled with a concrete density of $2300 \mathrm{~kg} / \mathrm{m}^{3}$, Young's modulus of $25 \times 10^{-9} \mathrm{~Pa}$, and Poisson's ratio of 0.33 . A $3 \%$ chloride sodium solution was used as the diffusion material (surface chloride load or $C s$ ). The concrete characteristics assumed for modeling are listed in Table 1 . The values used for each crack mode were based on the fact that the most important parameter for the rate of sodium chloride ingress included the characteristics of diffusion rate and that different values were assigned to this parameter in various conditions. The parameter values are also shown in Table 1.

\subsection{Geometric characteristics of models}

The modeling in this work was conducted by using COMSOL Multiphysics software [30]. Among the concrete specimens modeled, one served as the reference specimen with no cracking. The rest of the specimens had crack widths of $30,60,100$ (equivalent to a tenth of a millimeter), and $500 \mu \mathrm{m}$ (equivalent to half a millimeter). All the cracks were modeled in the middle of the specimens. The depths of crack in specimens were 50,100 , and $150 \mathrm{~mm}$ equivalent to $1 / 6,1 / 3$, and $1 / 2$ heights of the concrete specimens, respectively. In all the models, certain rebar locations (represented by lines) were considered to obtain the desired outputs by using the software and examine and compare the results. Each model included three vertical lines ( $a g$, $b h$, and $c i$ in Figure 1(a)) and three horizontal lines ( $a d$, $b e$, and $c f$ in Figure 1(a)), which denote the possible locations of rebars within concrete.

\subsection{Modeling software}

COMSOL multiphysics software is a comprehensive set for modeling. It is able to solve differential equations of nonlinear systems by partial derivations through Finite Element Method (FEM) in the spaces of 1, 2, or 3 dimensional. Compared to other software packages including finite elements, the most important advantage of this software is the simplicity of applying several different physics to models. This software was invented by the students of Royal Institute of Sweden Technology.

Extra-fine mode from the defaults of software was selected for meshing due to its high accuracy in investigating the results. The accuracy of this meshing (double zooming) for a specific sample is given in Figure 1.

\subsection{Modeling validation and verification}

In order to validate the results of software and modeling output, three types of modeling were conducted using COMSOL Multiphysics software and the results were compared with those of MATLAB modeling. Also, for verification, the results were compared with the findings of Jin et al. [31] and Wang and Ueda [20]. First, a sample with no crack was modeled in MATLAB

Table 1. Values of the parameters employed in modeling [29].

\begin{tabular}{ll}
\hline \multicolumn{1}{c}{ Parameter } & \multicolumn{1}{c}{ Calibrated value } \\
\hline Coefficient of chloride diffusion into concrete & $6 \times 10^{-11}\left(\mathrm{~m}^{2} / \mathrm{s}\right)$ \\
Diffusion coefficient of chloride-damaged areas (between crack and concrete) & $1.2 \times 10^{-9}\left(\mathrm{~m}^{2} / \mathrm{s}\right)$ \\
Diffusion coefficient of chloride in small cracks (width lower than $100 \mu \mathrm{m})$ & $2 \times 10^{-9}\left(\mathrm{~m}^{2} / \mathrm{s}\right)$ \\
Diffusion coefficient of chloride in large cracks (width larger than $100 \mu \mathrm{m})$ & $4 \times 10^{-9}\left(\mathrm{~m}^{2} / \mathrm{s}\right)$ \\
Chloride concentration (3\% solution of sodium chloride) & $523.4\left(\mathrm{~mol} / \mathrm{m}^{3}\right)$ pore solution \\
Size of damaged zone for small cracks (crack width less than $100 \mu \mathrm{m})$ & $1(\mathrm{~mm})$ \\
\hline
\end{tabular}




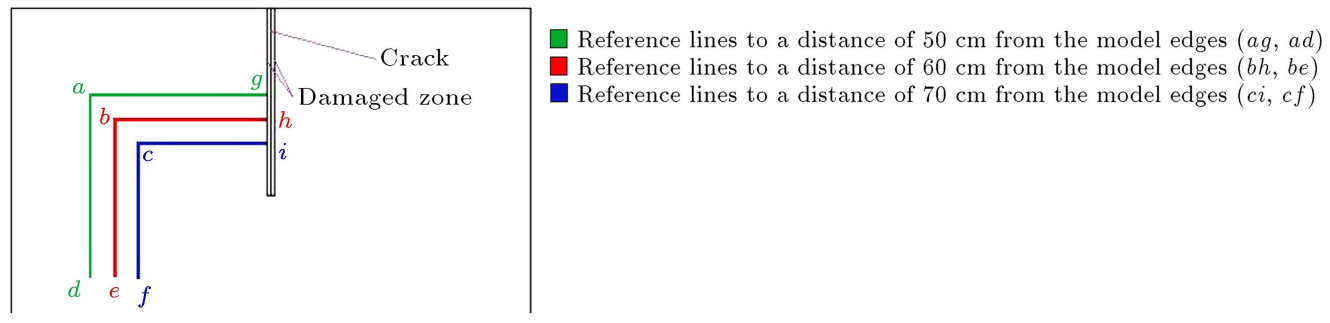

(a)

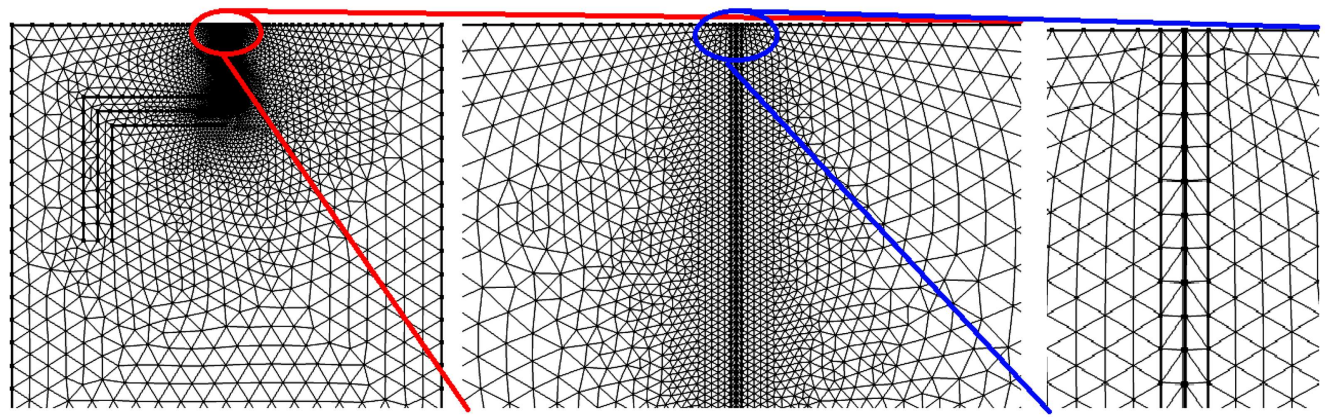

(b)

Figure 1. (a) Reference lines and (b) Meshing of one specimen $(2 \times$ magnification $)$.

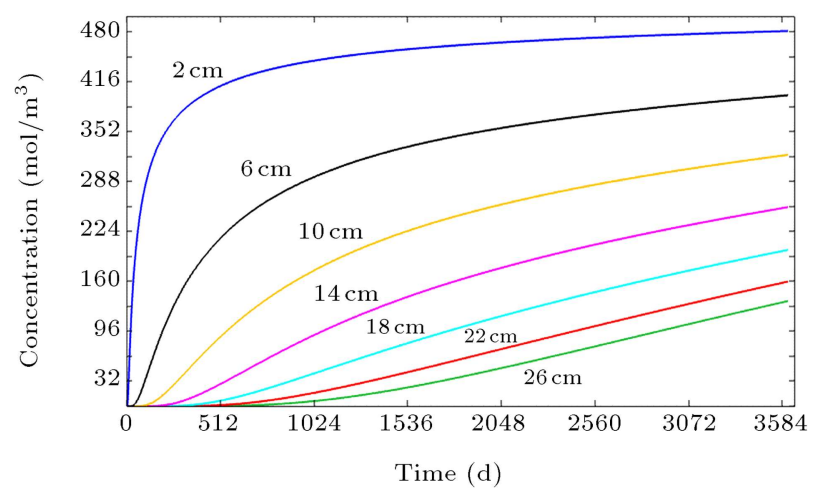

(a) Un-cracked concrete modeling results in COMSOL

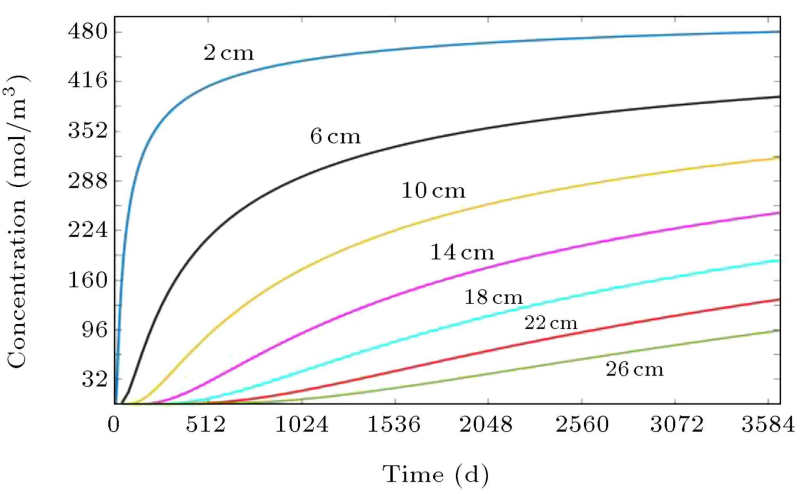

(b) Un-cracked concrete modeling results in MATLAB

Figure 2. The rate of chloride ion ingress in specific width sections (20,60, 100,140, 180, 220, and $260 \mathrm{~mm})$ at the end of 10 years.

and COMSOL and the diffusion rate of chloride ion was compared in specific horizontal sections $(20,60$, $100,140,180,220$, and $260 \mathrm{~mm}$ ) which showed good agreement with each other (Figure 2). In the research of Jin et al., five square concrete samples characterized by $100 \mathrm{~mm}$ in height, crack widths of $10,30,60,90$, and 120 microns in size, and crack depth of $30 \mathrm{~mm}$ were modeled. A relationship between crack diffusion rate $\left(D_{c r}\right)$ and crack width was proposed, based on which a specific diffusion rate for each crack was considered. Concrete samples were held under chloride pressure and a diagram was drawn for showing the rate of diffusion in 10 days. Similar modeling with the assumptions above was also done in COMSOL software. Based on Figure 3, it is clear that diagrams have good consistency with each other.

In another research, considering diffusion time of
10 hours and a crack width of $60 \mathrm{~mm}$, Wang and Ueda [20] calculated the value of chloride density by increasing the depth of crack based on the experimental data in Meso scale model of Ismail et al. [11]. In the simulation process, the diffusion rate of normal and cracked concretes was set to $1.1 \times 10^{-10} \mathrm{~m}^{2} / \mathrm{s}$ and $2.76 \times 10^{-6} \mathrm{~m}^{2} / \mathrm{s}$, respectively. In addition, the value of surface chloride concentration equal to $7.68 \times 10^{-3} \mathrm{~g} / \mathrm{cm}^{3}$ was considered. Through the mentioned assumptions, modeling was done by using COMSOL software and the obtained results showed good agreement with those of Wang and Ueda.

\section{Modeling results}

The effects of crack thickness and depth on various parts of the concrete specimens were illuminated on 


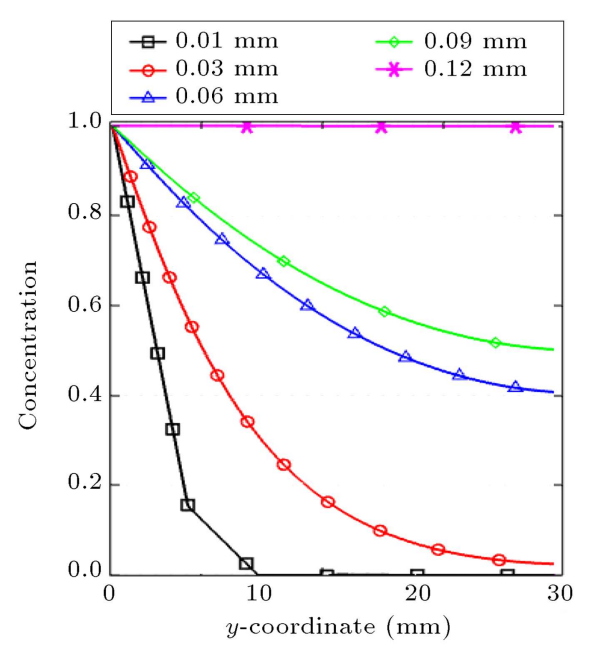

(a) Cracked concrete modeling results in present

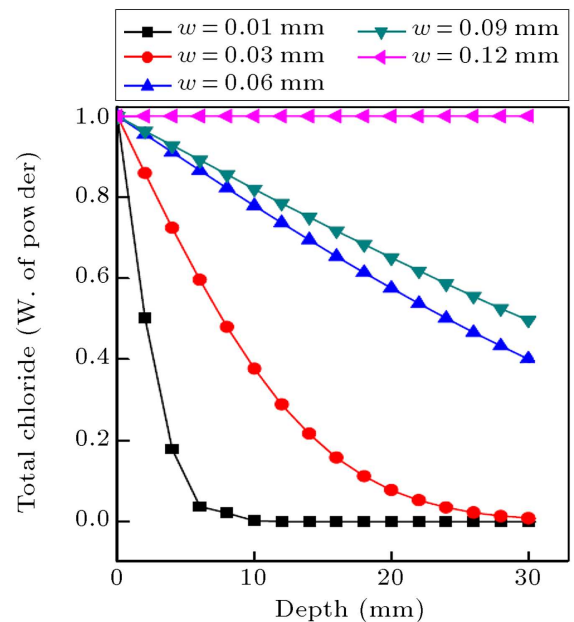

(b) Cracked concrete modeling results in Jin et al. [31]

Figure 3. The rate of chloride ion ingress due to crack at the end of 10 days.

the basis of the modeling and analysis results. In these diagrams, the horizontal axis represents time (measured in days), and the vertical axis denotes the rate of chloride diffusion (measured in $\mathrm{mol} / \mathrm{m}^{3}$ ). Some points about all of the figures in the following are worth discussing. The reference points and lines indicated in the figures are shown in Figure 1(a). In the analysis process, cracking was examined every day for the first 50 days. From the 51st day to the first year, cracking was examined every 10 days. After the first year up to the 10th year, cracking was examined every 50 days. In the presentation of results, two-day findings over the first 50 days are shown. From the 51st day to the first year, 20-day findings are presented. After the first year up to the end of the 10th year, 100-day findings are shown. This type of presentation was adopted to ensure the conciseness and easy interpretation of the data. In the diagrams drawn on the basis of the reference lines, the length of each line corresponds to the rate of chloride ion ingress all around the area covered by the line. Each vertical line in a diagram represents the rate of chloride ion ingress or a specific width on a reference line.

\subsection{General view of chloride ion diffusion in the modeled samples}

Chloride diffusion proceeding only from the upper borders of the concrete specimens was modeled. In the modeling of diffusion into cracks, diffusion initiating from crack borders was not represented and different diffusion rates were applied. As shown in Table 1, each cracked concrete specimen was assigned three diffusion rates: the first related to the healthy section of the specimen, the second associated with a crack, and the third related to the broken segment between a crack and the healthy section of the specimen. The final diffusion rate normally corresponds to the largest crack in a concrete structure; a fragile section that is smaller than a crack but larger than the healthy section of concrete exhibits the lowest diffusion rate. After meshing and applying the parameters listed in Table 1, the analyses were carried out over 3650 days (10 years) as the period in which diffusion was examined. The results are shown in Figure 4(a).

The chloride concentration at the end of the 3650th day is illustrated in Figure 4(a). As expected, increasing crack thickness and depth elevated the diffusion rate. A comparison of the specimens indicated that crack thickness exerted greater effect on chloride diffusion than crack depth. The comparison of chloride ingress in different periods into the uncracked specimen and the cracked specimen with a crack thickness of $500 \mu \mathrm{m}$ and a crack depth of $150 \mathrm{~mm}$ is shown in Figure 4(b).

Figure 4(b) shows that during the first few days, the concentration of chloride from a distance around the crack of the cracked specimen is less than that in the non-cracked sample. This finding indicated that in the first few days, chloride tended to penetrate more effectively into a crack. In cracked segments, therefore, more chloride will penetrate into the parts close to a crack up to a certain radius. The difference in the chloride penetration of cracked and un-cracked concretes will decrease with increasing distance from a crack.

\subsection{Rate of chloride diffusion on the basis of timing with respect to reference lines and points}

The set of diagrams displaying the rate of chloride diffusion into each reference line or point was intended to investigate and compare the rate of chloride concentration at each distance and point from the diffusion surface and crack in various specimens. The reference 


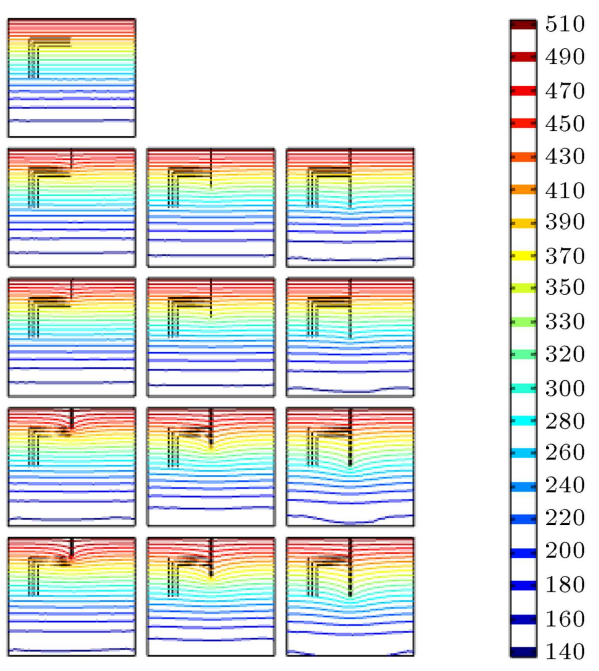

(a)

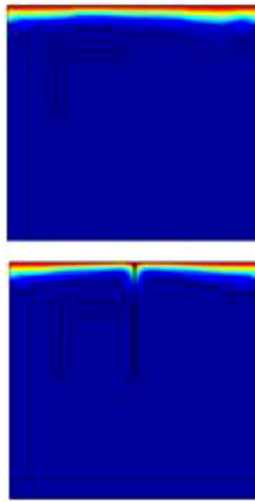

After 5 days

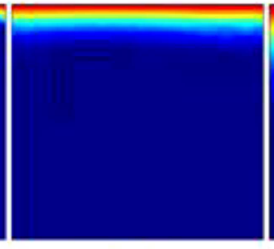

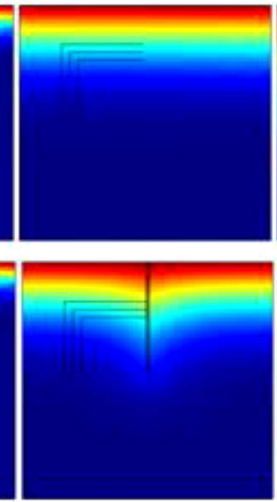

After 365 days

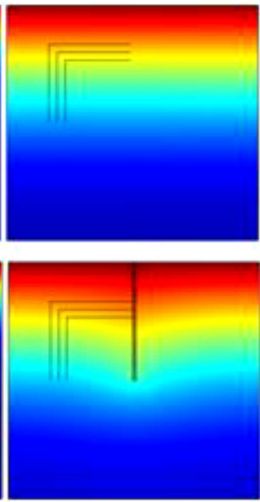

After 1825 days

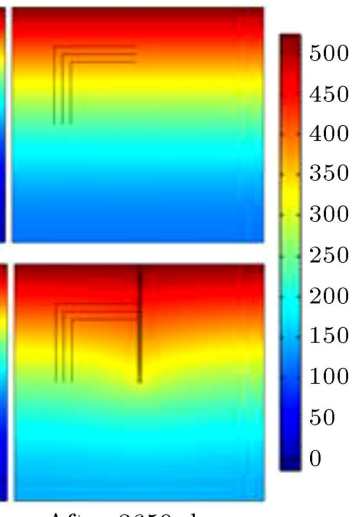

After 3650 days

(b)

Figure 4. (a) Chloride concentration in different samples on the 3650 th day (end of 10 years). (b) Chloride ingress in 5 and 50 days and 1,5 , and 10 years at the top of the un-cracked concrete specimen and bottom of the concrete sample with a $500 \mu \mathrm{m}$ wide and $150 \mathrm{~mm}$ deep crack.

lines represent hypothetical rebars with concrete cover including the distance covered, and the reference points represent the locations of the hypothetical rebars.

Each vertical line in Figure 5 shows the rate of chloride ion ingress into the reference line ad (see reference lines in Figure 1(a)) from the beginning to the end (located at the center of a specimen) of the line. The figure indicates that diffusion over time was nonlinear and that the difference among the models could sometimes be large or small. The 30 and $50 \mu \mathrm{m}$ cracks generally behave in a similar manner; the same is true for the 100 and $500 \mu \mathrm{m}$ cracks. A considerable difference in behavior occurred between the 50 and $100 \mu \mathrm{m}$ cracks primarily because of the increasing cracking zone in the specimens. Another interesting finding is that the $50 \mathrm{~mm}$ distance of reference line ad from the diffusion surface showed that the most extensive diffusion occurred in the un-cracked specimen up to about the 250th day. This finding is attributed to the tendency of chloride ions to pass through a crack

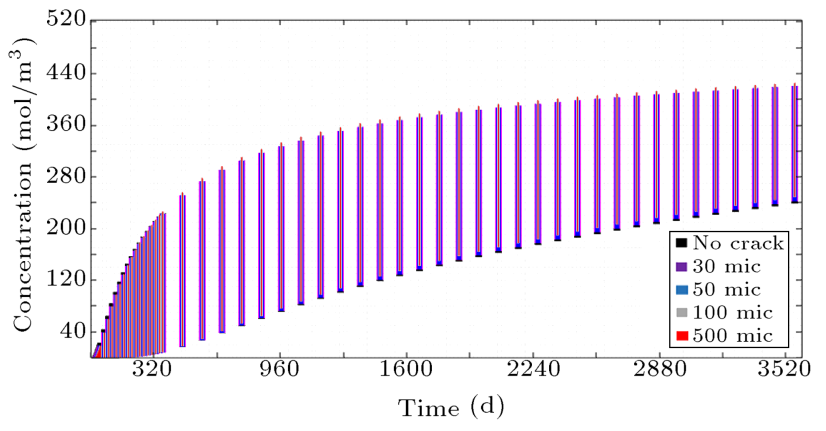

Figure 5. Comparison of the rate of chloride ion ingress into the specimen with a $50 \mathrm{~mm}$ crack and the un-cracked concrete sample (vertical reference line ad located $50 \mathrm{~mm}$ from the side of the sample).

instead of un-cracked parts. Thus, at a distance farther from a cracked specimen's center (where a crack is located), the concentration of chloride ions was initially lower than that in the un-cracked concrete, where ingress occurred uniformly all around the surface. 


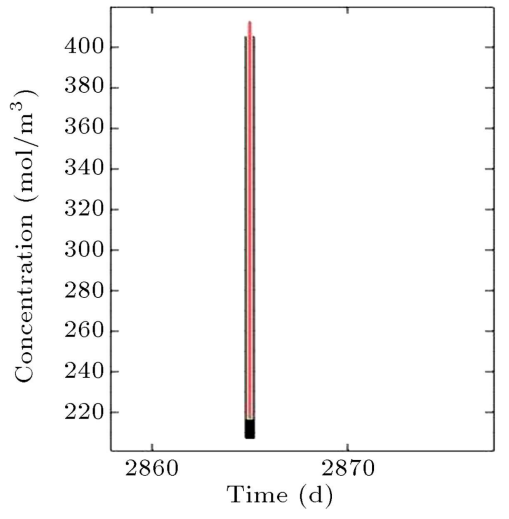

(a) Ingress into reference line ad

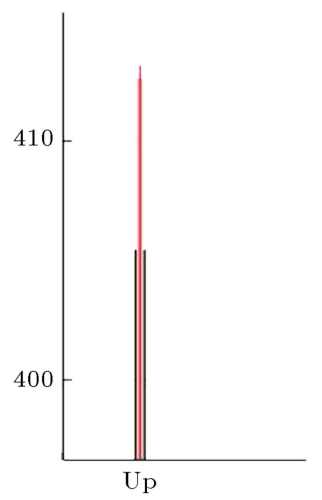

(b) Upstream ingress into reference point $a$

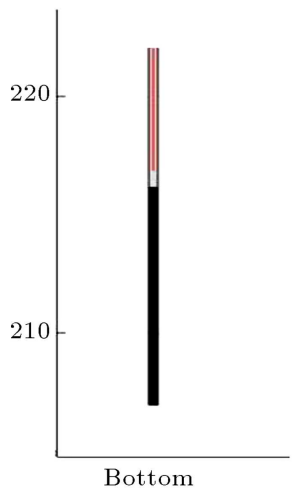

(c) Downstream ingress into reference point $d$

Figure 6. Magnified version of Figure 5 (reference line $a d$ ) on the 2865th day.

Figure 6 shows a magnified image of chloride diffusion on the 2865th day; the 30 and $50 \mu$ m cracks were eliminated from the figure. The top and bottom parts of the figure show that on the 2865th day, the highest chloride ion concentration was observed in the $500 \mu \mathrm{m}$ crack. The chloride diffusion rates of the 500 and $100 \mu \mathrm{m}$ crack were 413 and $412 \mathrm{~mol} / \mathrm{m}^{3}$, respectively. In the un-cracked specimen, the chloride diffusion rate was $405 \mathrm{~mol} / \mathrm{m}^{3}$. The lowest rates of diffusion on the 2865th day were 216,215 , and $206 \mathrm{~mol} / \mathrm{m}^{3}$.

Figures 5 and 7 indicate that up to the first 50 days, corrosion due to chloride ion concentration was the most prevalent in the un-cracked concrete sample. This trend continued up to the 80th day and declined thereafter. As previously stated, from about the 250th day, the cracked concrete samples gradually showed more chloride concentration than the un-cracked sample. Up to the 500th day, all the cracked samples exhibited more chloride concentration in the reference line ad than the un-cracked sample in the same reference line. On the 3600th day, at the highest point of reference line $a d$, the rate of chloride diffusion into the un-cracked concrete sample was $418.46 \mathrm{~mol} / \mathrm{m}^{3}$; the rate of chloride diffusion into

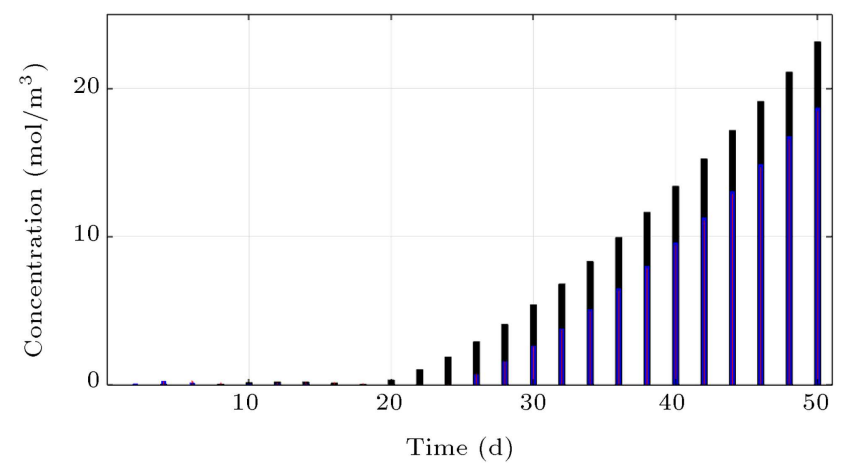

Figure 7. Magnified version of Figure 5 (specimens with 30 and $100 \mu \mathrm{m}$ cracks eliminated) for the first 50 days.

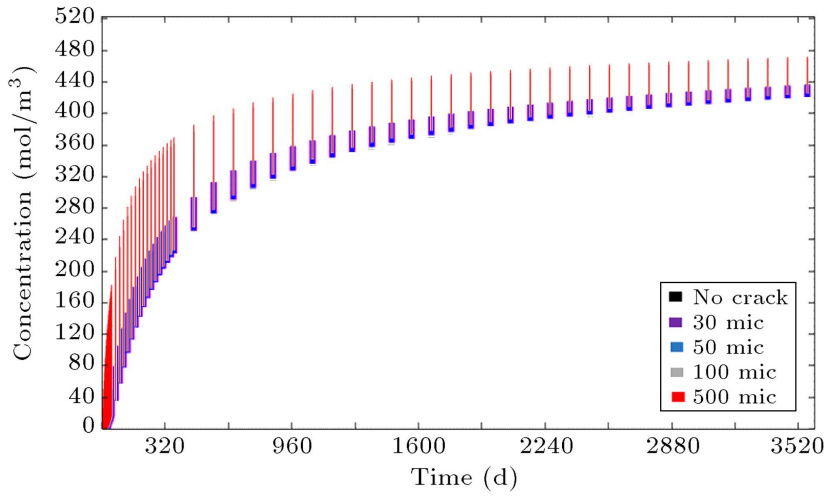

Figure 8a. Comparison of the rate of chloride ion ingress into the concrete sample with a $50 \mathrm{~mm}$ crack and un-cracked concrete sample (reference line ag located $50 \mathrm{~mm}$ from the top of the sample).

the concrete sample with a $500 \mu \mathrm{m}$ wide and $50 \mathrm{~mm}$ deep crack was $425.68 \mathrm{~mol} / \mathrm{m}^{3}$.

The reference lines in Figure 8a are horizontal (line $a g$ ) and span $3 \mathrm{~mm}$ (from the sample center, beside the crack) to $50 \mathrm{~mm}$ of its edge. As illustrated in the figure, from the very first days of the observation, the samples with 100 and $500 \mu \mathrm{m}$ cracks showed more concentration of chloride ions than the un-cracked sample. In the third and fourth days, all the cracked samples showed a higher chloride concentration in reference line $a g$ than the sample without cracks. This result is ascribed to the closeness of the right side of reference line $a g$ to the cracks; at the time of diffusion, more chloride ions penetrated into the cracks. In Figures $8 \mathrm{a}$ and $8 \mathrm{~b}$, the black portions, which represent chloride ion diffusion into the un-cracked sample, are also represented with dotted lines because chloride ion ingress from the top to the bottom of the sample was uniform. Thus, the horizontal reference line shows only one concentration level for this sample in different periods.

The magnified image of chloride diffusion on the 3600th day (Figure 8a) is provided in Figure 8b. 


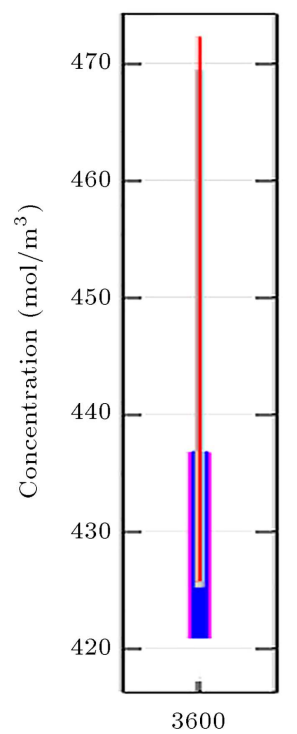

Figure 8b. Magnified image of the 3600th day in Figure $8 \mathrm{a}$.

The highest chloride concentration was observed in the concrete specimen with a $500 \mu \mathrm{m}$ crack, and the diffusion rate was $473 \mathrm{~mol} / \mathrm{m}^{3}$. As expected, the lowest chloride concentration was observed in the uncracked concrete, with chloride diffusing at a rate of $418 \mathrm{~mol} / \mathrm{m}^{3}$.

Each vertical line in Figure 9 represents the chloride ion ingress rate in line of from the beginning to the end (center of a sample) of the line. Despite the increase in crack depth, the concentration of chlorine ions is generally three times less than that shown in Figure 5. This difference is due to increase in cover distance of the closest probable rebar to $20 \mathrm{~mm}$. Note that despite the reference line nearing the center of the concrete samples (i.e., the location of cracks), the chloride diffusion rate minimally increased; however, such diffusion was lower than ever because the concrete cover of the rebar was farther from the diffusion surface

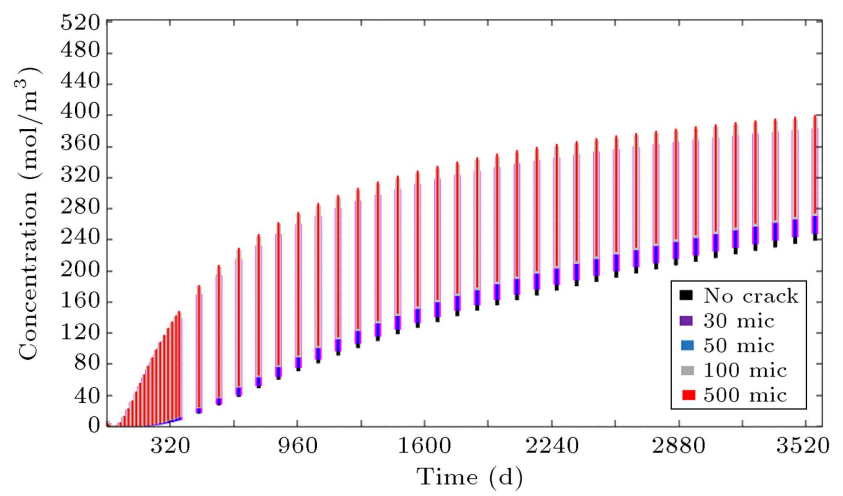

Figure 9. Comparison of the rate of chloride ion ingress in the concrete sample with a $150 \mathrm{~mm}$ crack and un-cracked concrete sample (reference line $c f$ located $70 \mathrm{~mm}$ from the edge of the sample).

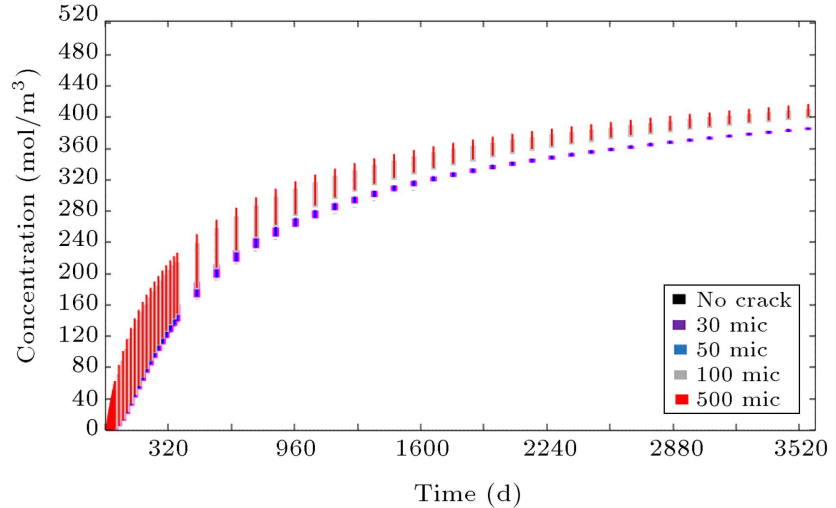

Figure 10. Comparison of the rate of chloride ion ingress in the concrete sample with a $70 \mathrm{~mm}$ crack and un-cracked concrete sample (horizontal reference line $c i$ located $70 \mathrm{~mm}$ from the top of the sample).

by $20 \mathrm{~mm}$. This feature exerted greater effect on the rate of chloride ion ingress than the increase in crack depth to $100 \mathrm{~mm}$, thus resulting in rebar corrosion. An increase in rebar cover causes corrosion. This trend naturally depends on the distance from cracks, as demonstrated in Figure 10, wherein the reference line, instead of vertical line $c f$, is represented as horizontal line $c i$. Each vertical line in the figure shows the rate of chloride ion ingress into line $c i$.

As indicated in Figure 10, cover distance was fixed at $70 \mathrm{~mm}$, but chloride ion concentration increased. This finding reflects closeness to the cracks; reference line $c i$ begins from the distances near the cracks.

As presented in the calculations in Figure 11, up to the 210th day, the highest concentration of chloride ions was observed in the un-cracked concrete because of the tendency of chloride ions to pass through cracks instead of un-cracked segments. From about the 560th day up to the 2170 th day, chloride ion concentration in

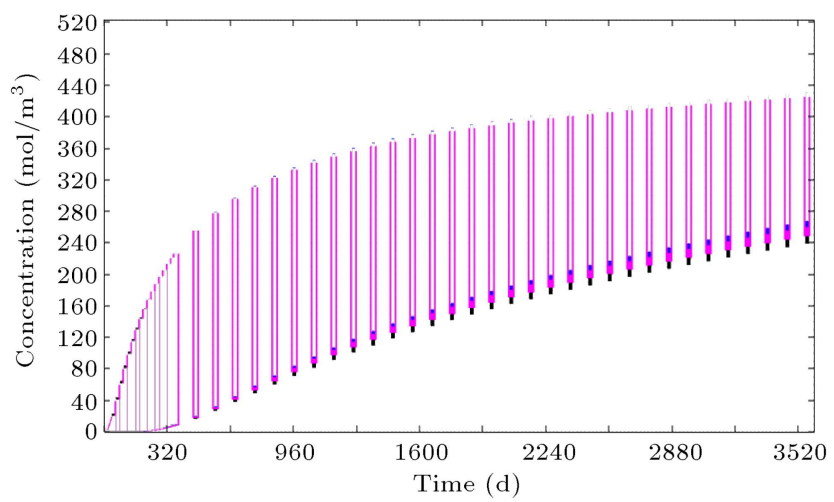

Figure 11. Comparison of the rate of chloride ion ingress in the concrete samples with a crack $100 \mu \mathrm{m}$ wide and 50 , 100 , and $150 \mathrm{~mm}$ deep and un-cracked concrete (reference line ad located in $500 \mathrm{~mm}$ of the sample's left edge, it starts from $500 \mathrm{~mm}$ of the sample's upper surface and continues to the middle of sample). 


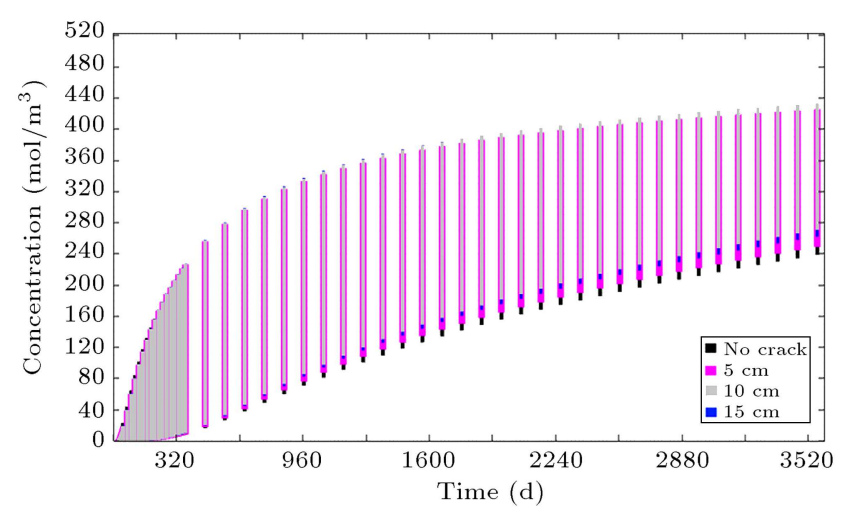

(a) $500 \mu \mathrm{m}$ crack

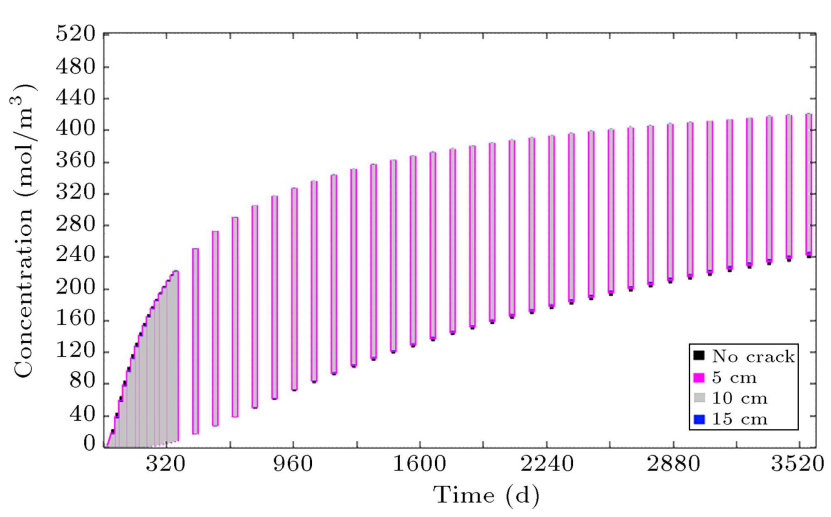

(b) $30 \mu \mathrm{m}$ crack

Figure 12. Comparison of the rate of chloride ion ingress in the concrete samples with different crack.

the reference line $a g$ in the specimen with a crack depth of $100 \mathrm{~mm}$ was higher than that in the specimen with a crack depth of $150 \mathrm{~mm}$. Before and after these depth ranges, chloride ion concentration was higher in deep cracks, thus confirming the uncertainty and relativity of physical crack characteristics (depth, thickness, and cracking zone stemming from a crack) as factors in determining the corrosion rate. For each specific rebar in concrete, a crack characterized by specific conditions appears to be more harmful than other cracks in different periods. For a more accurate comparison of the data discussed above, two cracking modes, namely 30 and $500 \mu \mathrm{m}$ cracks, were incorporated into the modeling.

Figure 12 shows a barely noticeable difference in chloride ion diffusion at various depths $(50,100$, and $150 \mathrm{~mm}$ ) for the specimen with a $30 \mu \mathrm{m}$ crack; chloride ion concentration all around the figure indicated that such concentration was higher in $100 \mathrm{~mm}$ cracks than that in $150 \mathrm{~mm}$ cracks (until the end of the 10th year). This finding demonstrates that a critical crack of specific length and width occurs for each type of rebar installed in concrete; increasing each parameter is the only measure for preventing critical conditions in such rebars. Dotted lines were incorporated into the figures to simultaneously investigate all the models with different widths and depths. This approach was necessary because the results obtained from the connecting points of chloride concentration in each period were derived from one reference point and were all represented as curves (in the analyses, the reference point shown in Figure 1 is the point at which corrosion rate is calculated and represented; such a point can serve as the hypothetical location of rebars considering cover distance).

Because the extent of corrosion in Figure 13 and other similar diagrams is very high, these diagrams can be better analyzed through magnified versions of the images.

Figure 14 suggests that based on the initial days of observation, the reference point in the uncracked specimen exhibited the highest chloride ion concentration. The concentration that differed most considerably from all the other concentrations was that found in the specimen with a $100 \mu \mathrm{m}$ wide and $150 \mathrm{~mm}$ deep crack. Chloride concentration was the highest in the specimen with a $500 \mu \mathrm{m}$ wide and $100 \mathrm{~mm}$ deep crack, whereas such concentration was the lowest in the specimen with a $30 \mu \mathrm{m}$ wide and $150 \mathrm{~mm}$ deep crack (days before the 18th, Figure 14). The concentrations should, in practice, be very low and close to zero, but the same cannot be said for the samples up to the 10 th day. This problem stems from the inadequate accuracy

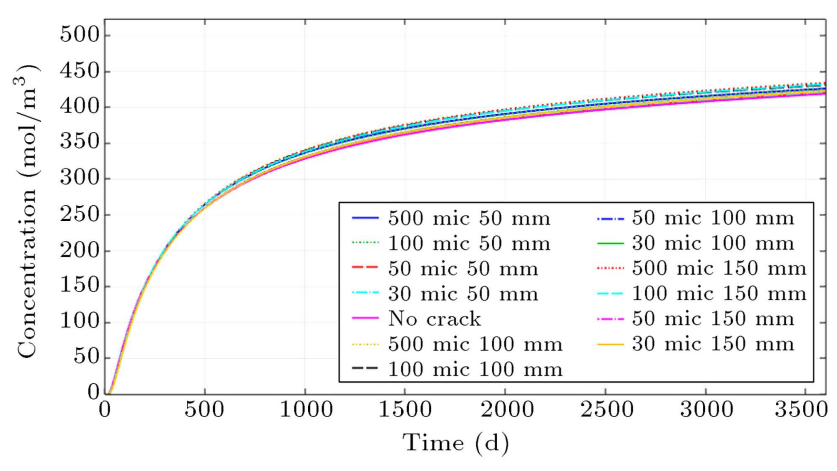

Figure 13. Chloride ion ingress into the reference point $a$.

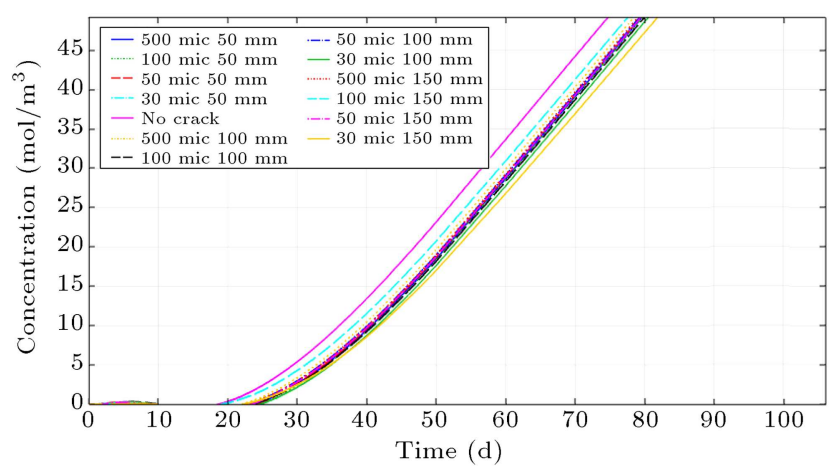

Figure 14. Magnified version of Figure 13, zoomed image of the first 100 days. 


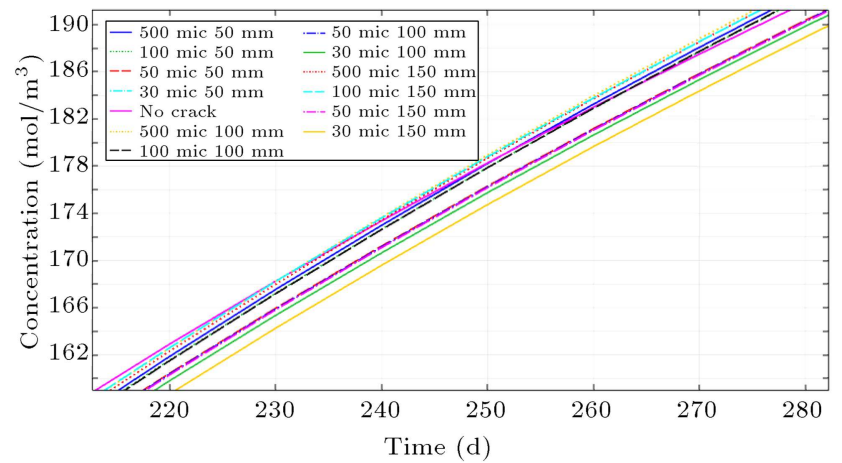

Figure 15. Magnified version of Figure $8 \mathrm{~b}$ for the interval of around 201 to 280 days.

of the daily analysis; however, because our analysis spans a long-term horizon (10 years), the aforementioned inadequacy can be disregarded. As presented in Figure 15, the un-cracked sample gradually lost the largest proportion of chloride concentration, and some displacements of the cracks occurred with the highest concentrations of chloride ions. These displacements began on the 250th day and lasted until the 600th day. Beyond this period, the positions of the cracks remained fixed, and the concentration of chloride ions in each crack steadily increased. The magnified version of Figure 13, showing the scenario at the end of the 10th year, is provided in Figure 16.

Figure 16 reveals that at the end of the 10 th year, the rate of chloride ion diffusion in the reference point was highest at a distance of $50 \mathrm{~mm}$ from the top and left sides of the modeled specimen with a $500 \mu \mathrm{m}$ wide and $150 \mathrm{~mm}$ deep crack. The next highest rate of diffusion was observed in the specimen with a $500 \mu \mathrm{m}$ wide and $100 \mathrm{~mm}$ deep crack, followed by the specimen with the $100 \mu \mathrm{m}$ wide and $150 \mathrm{~mm}$ deep crack. On the basis of these findings, a zone wherein the diffusion level is relatively close (meeting the distance of concrete cover), the width of cracks is a more important factor in corrosion than the depth of cracks. This conclusion can be confirmed by a comparison of the images of reference point $c$, which is located $700 \mathrm{~mm}$ away from the top and

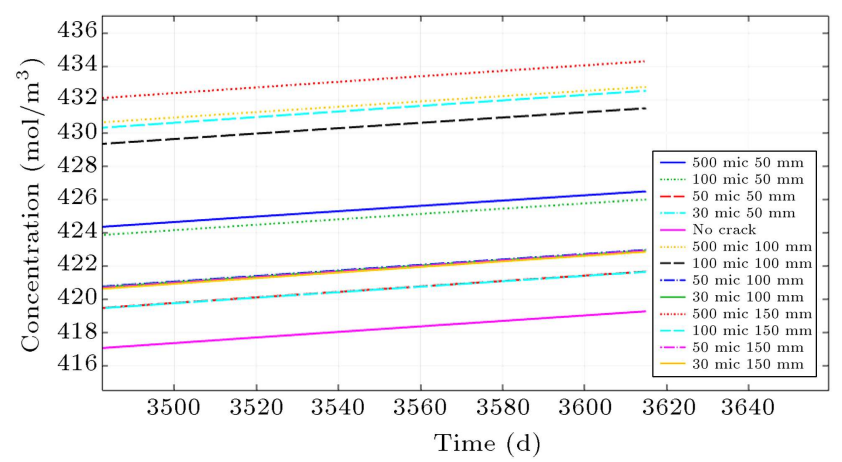

Figure 16. Chloride ion concentration in the reference point $a$.

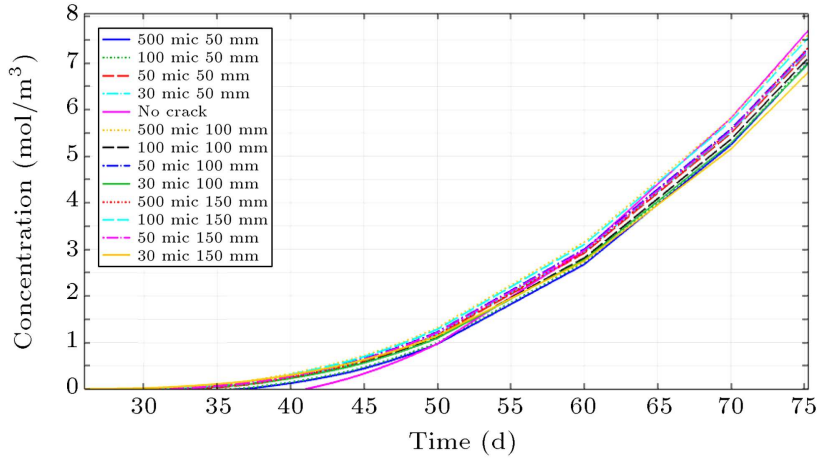

Figure 17. Chloride ion concentration in the reference point $c$, zoomed image of the interval of 20 to 75 days.

left sides of the modeled specimens. The sample with a $30 \mu \mathrm{m}$ wide and $50 \mathrm{~mm}$ deep crack differed slightly from the specimen with a $50 \mu \mathrm{m}$ wide and $50 \mathrm{~mm}$ deep crack, with the former exhibiting the lowest chloride diffusion. The un-cracked sample had the least chloride ion diffusion.

Magnification was repeated for the reference point $c$ (Figure 17).

Figure 17 shows that at the interval between the 20th and 75th days, many displacements occurred in the samples that registered the highest concentrations, and many irregularities were observed in the curves that reflect the highest chloride concentrations. In this instance, the un-cracked sample did not have the highest chloride ion concentration from the very first days of the observation. This finding is ascribed to the reference point being close to the cracks. Ultimately, because more chloride ions penetrate along the cracks, the un-cracked specimen exhibited the highest chloride ion concentration in the reference point $c$ for a short duration at the interval between the 70 th and 120 th days. After this period, however, concentration soon decreased. Chloride ion concentration in the un-cracked specimen ultimately reached its lowest level around the 320th day. Since then, the displacement trend stabilized up to the 10th year, as shown in Figure 18.

Figures 17 and 18 differ in that chloride ion

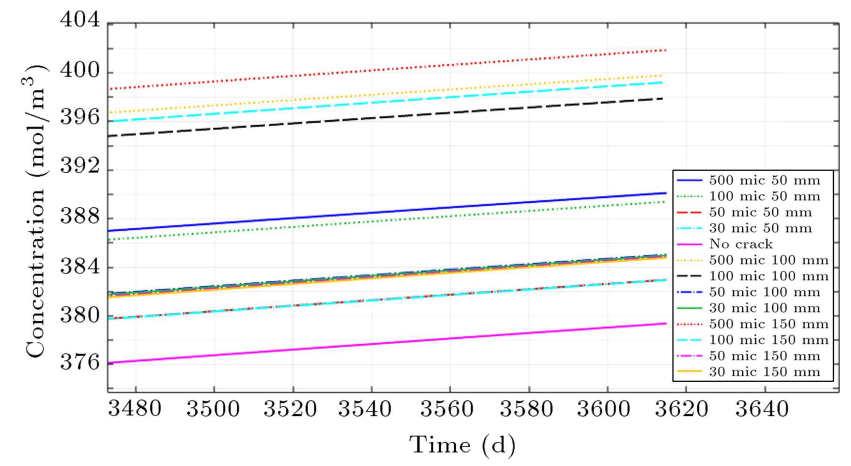

Figure 18. Chloride ion concentration in the reference point $c$ at the end of the 10 th year. 


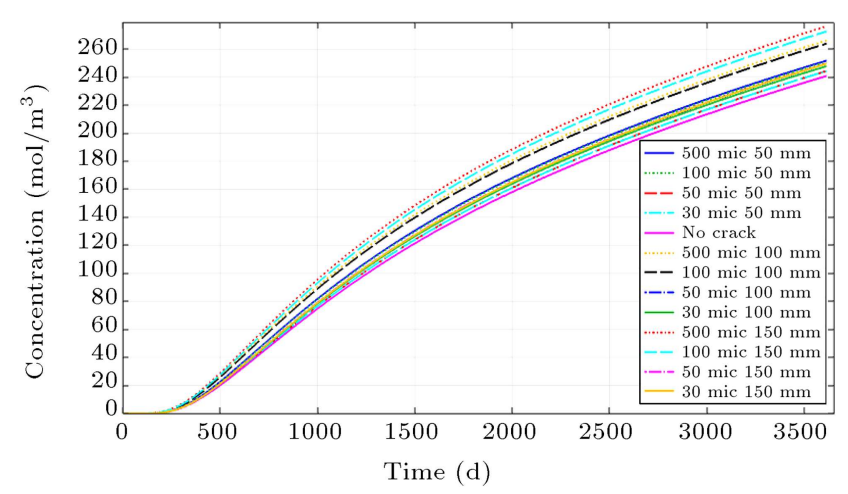

Figure 19. Chloride ion ingress into the reference point $f$.

concentration in the former is generally lower than that in the latter; they are similar (only partially different) in terms of the location of cracks toward one another. The concentration in the reference point $c$ was lower than that in the reference point $a$, indicating that diffusion occurred only from the upper surface of the sample and that despite the $20 \mathrm{~mm}$ closeness of the reference point $c$ to the cracks, it was located far from the diffusion level (upper surface) by about $20 \mathrm{~mm}$. As mentioned earlier, cover corrosion (at a distance from the diffusion surface and edge) is one of the most important factors in preventing rebar corrosion.

Reference point $f$ (distances of 70 and $150 \mathrm{~mm}$ from the left and upper surfaces of the specimens, respectively) is illustrated in Figure 19. Unlike the other figures, this one does not reflect numerous irregularities among the cracks' curves. When a reference point is located at an adequate distance from both diffusion surfaces and cracks, the irregularities of the two previous modes will occur less frequently; when a reference point is close to both diffusion surfaces and cracks, more displacements will occur. These phenomena confirm that only one or some critical cracks exist for each rebar in a specific period (crack with the highest chloride concentration); such cracks do not necessarily have the largest width or depth.

Figure 19 shows that the specimen with a $100 \mu \mathrm{m}$ wide and $150 \mathrm{~mm}$ deep crack had less chloride concentration than that found in the specimen with a $500 \mu \mathrm{um}$ wide and $150 \mathrm{~mm}$ deep crack. This result contrasts with that derived for the two previous modes and shows that when a reference point is far from a specific zone but near a diffusion surface and crack (in contrast to the situation in the two previous modes), crack depth is a more important factor than crack width.

Figures 20 and 21 compare three reference points $(a, b, c)$ in the un-cracked concrete specimen, the specimen with a $500 \mu \mathrm{m}$ wide and $150 \mathrm{~mm}$ deep crack (Figure 20), and the specimen with a $500 \mu \mathrm{m}$ wide and $50 \mathrm{~mm}$ deep crack (Figure 21).

Figures 20 and 21 show that the un-cracked sample, in which the reference point was $70 \mathrm{~mm}$ away

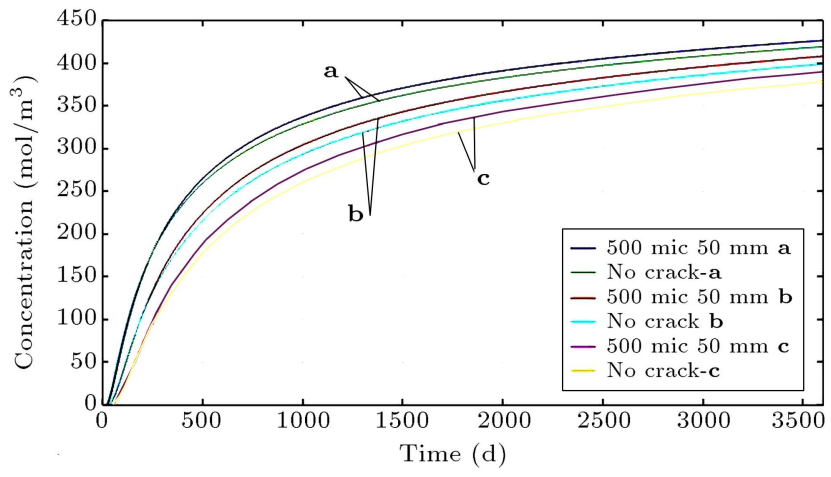

Figure 20. Comparison of chloride ion ingress into the reference points $a, b$, and $c$ in the un-cracked sample and the sample with a $500 \mu \mathrm{m}$ wide and $50 \mathrm{~mm}$ deep crack.

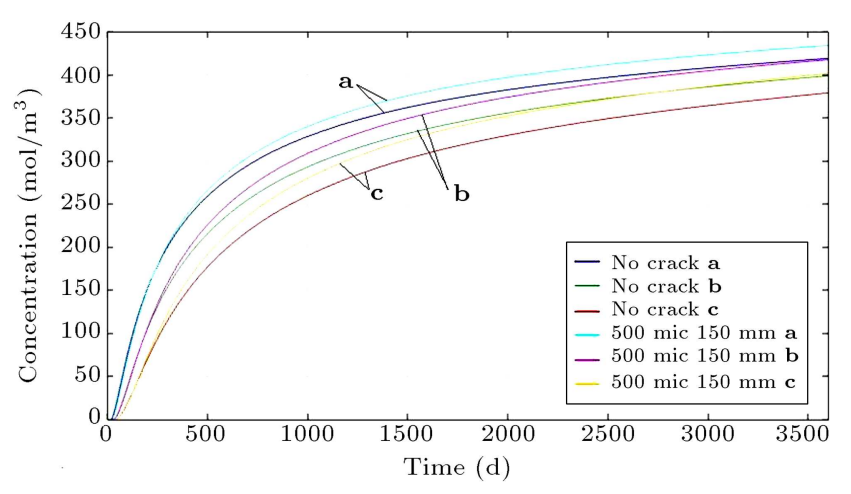

Figure 21. Comparison of chloride ion ingress into the reference points $a, b$, and $c$ in the un-cracked sample and the sample with a $500 \mu \mathrm{m}$ wide and $150 \mathrm{~mm}$ deep crack.

from the top and left sides of the sample (concrete cover of $70 \mathrm{~mm}$ or reference point $c$ ), exhibited the lowest concentration of chloride ions. These figures also indicate that the reference point $a$ had the highest chloride concentration, highlighting the importance of concrete cover in preventing chloride ion ingress.

Figures 22 and 23 show noteworthy points regarding the cracks; these points were nearer to the cracks than the points illustrated in the previous diagrams. As can be seen from Figure 22(a), at around the time intervals, no specific displacement occurred among the lines-a finding that contrasts with those presented in the previous diagrams. This is because the reference point was very close to the crack and the diffusion surface and because reference point $g$ was close enough to the cracks with less depth (unlike, for example, reference point $i$, which was somehow far from the cracks with a depth of $50 \mathrm{~mm}$ ). Thus, everything was advanced as expected, and a crack was more critical from the beginning of the observation to the 10th year, during which the cracks exhibited the greatest thickness and depth near point $g$ (cracks with a depth of $50 \mathrm{~mm}$ ). In the entire analysis, the lowest chloride ingress rate occurred in the uncracked sample; the other specimens were cracked in 


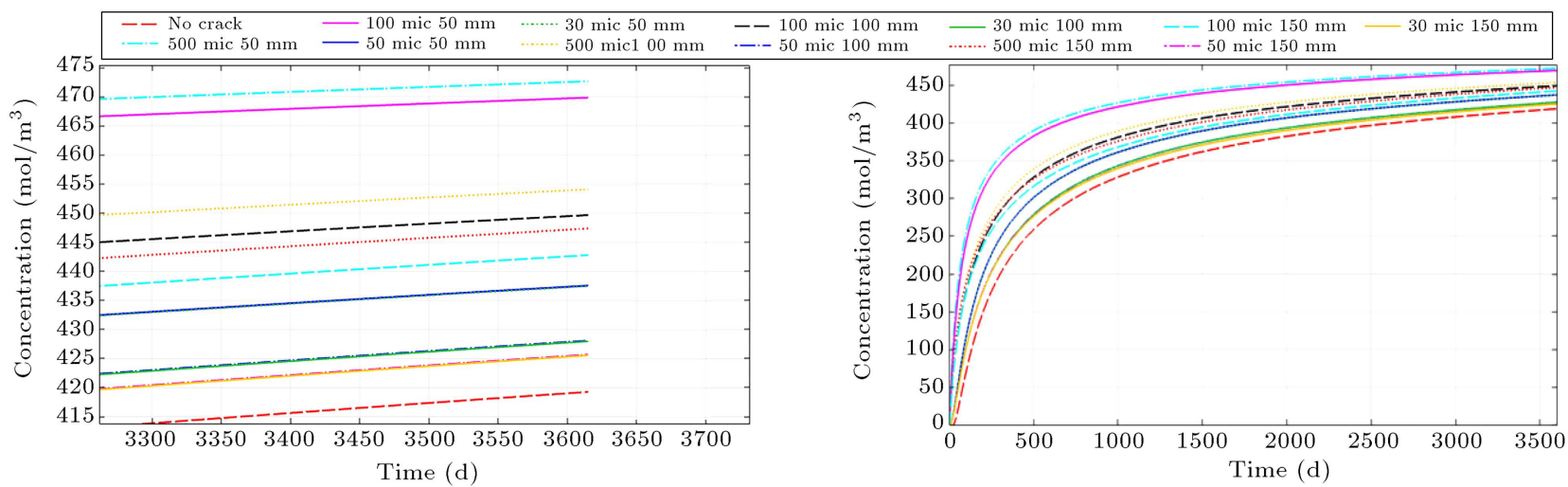

(a)

(b)

Figure 22. Comparison of chloride ion ingress into the reference point $g$ in the (a) initial days of observation (zoomed) and $(b)$ in all analysis periods.

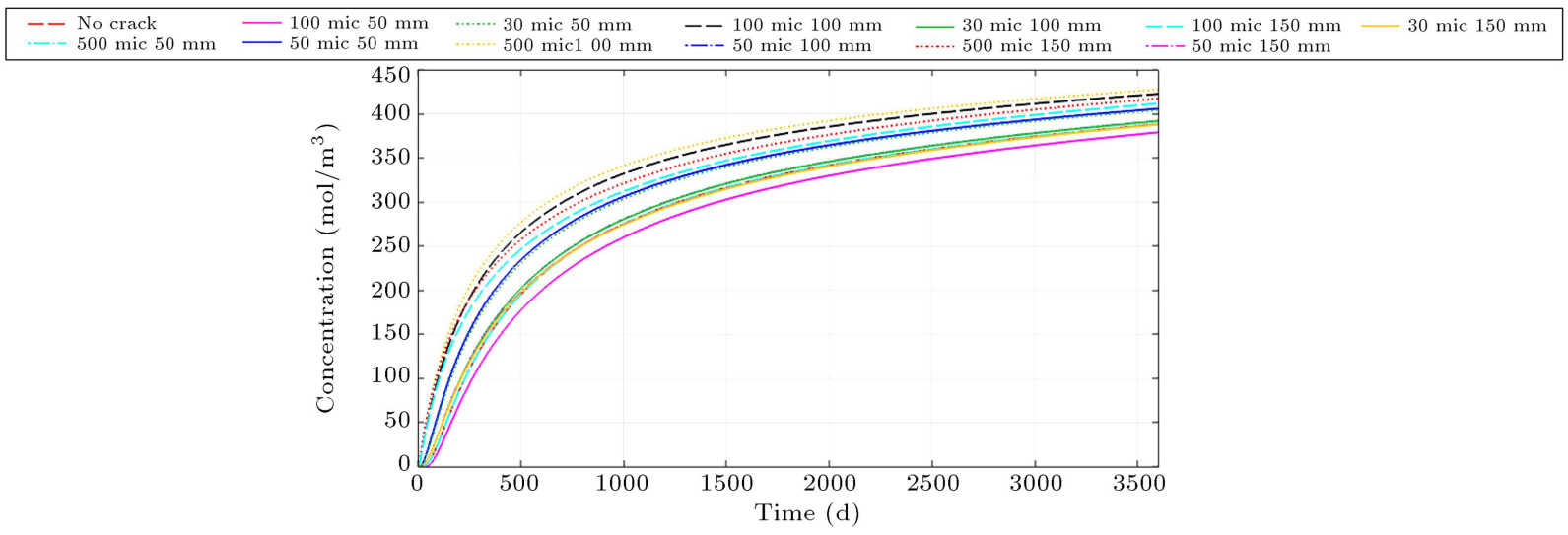

(a)

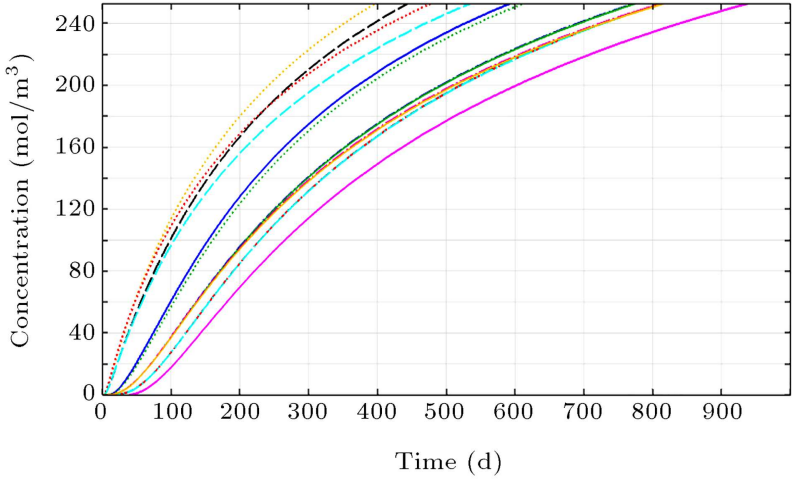

(b)

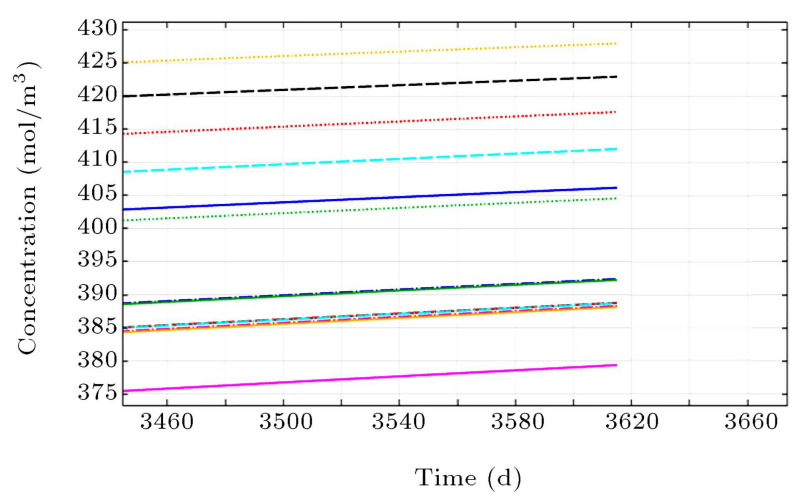

(c)

Figure 23. Comparison of chloride ion ingress into the reference point $i$ : (a) in all analysis periods, (b) initial days of observation (zoomed), and (c) final days of observation (zoomed).

accordance with the importance of thickness and depth factors. The accuracy of this problem can be clarified when the reference point examined was changed from $g$ to $i$. As seen in Figure 23(c), despite the reference point being located at a horizontal distance from the cracks, some irregularities and displacements occurred, similar to the situation seen within the initial days of observation. This finding is attributed to the fact that the reference point was located far from the diffusion point. However, because point $i$ was still close to the cracks, the trend of irregularities somehow ended at the end of the first year. Figure 23(a) shows that the cracked concrete sample with the greatest thickness and the crack depth nearer to reference point $i$ (i.e., $100 \mathrm{~mm}$ ) was the specimen that exhibited the critical crack, as expected. 


\section{Conclusions}

A numerical simulation study was conducted to evaluate effects of cracks on chloride diffusion and corrosion initiation in RC structures, and the following result was obtained:

- All the figures show that the most important factor in chloride ion ingress into the concrete samples was the distance from the diffusion surface. Given that such ingress causes rebar corrosion in the reinforced concrete, concrete cover is a critical factor in the analysis of chloride ingress and rebar corrosion;

- Over time, critical cracks do not always occur in specific parts of the concrete samples. In a specific location and different times, critical cracks were not necessarily those with the greatest thickness and depth. Nevertheless, over time, considerably wide and deep cracks may ultimately reflect the substantial ingress rate;

- Generally, crack thickness exerted more effects than crack depth on the rate of chloride ion diffusion and on relatively far points from the cracks. When the reference points were relatively close to the cracks, however, crack depth was the more important factor. Depending on the closeness of rebars, rebar corrosion can increasingly accelerate under a crack depth and rebar location that is conducive to such corrosion. The insight derived from the findings is that depending on rebar location in the reinforced concrete, the critical depth of a crack is not based on the greatest depth, but on the correspondence between crack depth and rebar location;

- Crack thickness exerted more effects than crack depth in most of the modes (time or location). This finding is attributed not only to crack thickness, for which the importance of a cracked zone was demonstrated, but also to the increase in crack thickness. Under this situation, the thickness of a cracked zone also increased, thereby leading to increased chloride ion ingress into concrete;

- In the points relatively far from the cracks, the uncracked sample, up to a noticeable period, registered the highest chloride ion concentration. This phenomenon is due to the fact that when concrete is un-cracked, chloride ion ingress into concrete and its entire surface is almost the same. Cracking typically penetrates concrete from the weak side of the material, thus ensuring the relative safety of points farther from cracks against chloride ion ingress as time passes;

- To determine the initiation of corrosion, critical chloride concentration should be used as a factor of analysis. This issue was not covered in this research. To compare concrete zones on the basis of distance from a diffusion surface and a crack, the time at which the approximate concentration in the studied zones is reached can be compared with half of the surface chloride loading rate. In the reference point $a$, which represents the points relatively near the diffusion level (or meeting the thickness of concrete cover), the time at which half of the surface chloride loading rate is reached for all the cracks is around the 500th day, with little difference occurring among the cracks. In point $f$, which represents the points relatively far from the cracks and diffusion surface, this phenomenon occurred for the specimens with a $100 \mu \mathrm{m}$ wide and $100 \mathrm{~mm}$ deep crack exactly at the end of the 10th year. For the 100 and $500 \mu \mathrm{m}$ cracks with a depth of $150 \mathrm{~mm}$, the chloride ion concentration was little more than half of the surface chloride loading rate; for the other cracks, the chloride concentration was slightly less than the chloride loading rate. For the point $g$, which represents the points close to the diffusion surface and cracks, the specimens with the 100 and $500 \mu \mathrm{m}$ cracks at a depth of $50 \mathrm{~mm}$, half of the surface chloride loading rate was reached around the 50th day. For the un-cracked sample, this rate was reached around the 500th day. For the rest of the specimens, this rate was reached in the days between the 50th and 500th days. Finally, the surface chloride loading was reached for point $i$, which was near the cracks and far from the diffusion surface, around the 400th day in the sample with a $500 \mu \mathrm{m}$ wide and $100 \mathrm{~mm}$ deep crack; for the uncracked sample, this rate was reached on the 1000th day; for the rest of the specimens, the rate was reached in the days between the 400th and 100th days.

\section{References}

1. Neville, A.M., Properties of Concrete, Fourth and Final Edition Standards, Prentice-Hall, Incorporated, Englewood Cliffs, NJ USA (1996).

2. MacGregor, J.G., Reinforced Concrete: Mechanics and Design, Prentice-Hall, Incorporated, Englewood Cliffs, NJ USA (1992).

3. Dhinakaran, G. and Sreekanth, B. "Physical, mechanical, and durability properties of ternary blend concrete", Scientia Iranica, 25(5), pp. 2440-2450 (2018).

4. Tuutti, K. "Service life of structures with regard to corrosion of embedded steel", Special Publication, 65, pp. $223-236$ (1980).

5. Priyanka, C., Vijayalakshmi, B., Nagavalli, M., and Dhinakaran, G. "Strength and durability studies on high volume readymade ultrafine slag based high strength concrete", Scientia Iranica, 26(5), pp. 26242632 (2019). 
6. Shayanfar, M.A., Barkhordari, M.A., and GhanooniBagha, M. "Effect of longitudinal rebar corrosion on the compressive strength reduction of concrete in reinforced concrete structure", Advances in Structural Engineering, 19(6), pp. 897-907 (2016).

7. Shayanfar, M.A., Barkhordari, M.A., and GhanooniBagha, M. "Probability calculation of rebars corrosion in reinforced concrete using css algorithms", Journal of Central South University, 22(8), pp. 3141-3150 (2015).

8. Ghanooni-Bagha, M., Shayanfar, M.A., ShirzadiJavid, A.A., and Ziaadiny, H. "Corrosion-induced reduction in compressive strength of self-compacting concretes containing mineral admixtures", Construction and Building Materials, 113(1), pp. 221-228 (2016).

9. Ghanooni-Bagha, M., Shayanfar, M.A., Reza-zadeh, O., and Zabihi-Samani, M. "The effect of materials on the reliability of reinforced concrete beams in normal and intense corrosions", Journal of Eksploatacja I Niezawodnosc, 19(3), pp. 393-402 (2017).

10. Rahmani, K., Ghaemian, M., and Hosseini, A. "Experimental study of the effect of water to cement ratio on mechanical and durability properties of nano-silica concretes with polypropylene fibers", Scientia Iranica, 26(5), pp. 2712-2722 (2018).

11. Ismail, M., Toumi, A., François, R., and Gagné, R. "Effect of crack opening on the local diffusion of chloride in cracked mortar samples", Cement and Concrete Research, 38(8), pp. 1106-1111 (2008).

12. Ismail, M., Toumi, A., Francois, R., and Gagné, R. "Effect of crack opening on the local diffusion of chloride in inert materials", Cement and Concrete Research, 34(4), pp. 711-716 (2004).

13. Shayanfar, M.A., Barkhordari, M.A., and GhanooniBagha, M. "Estimation of corrosion occurrence in RC structure using reliability based PSO optimization", Periodica Polytechnica, Civil Engineering, 59(4), pp. 531-543 (2015).

14. Andrade, C., Alonso, C., and Molina, F.J. "Cover cracking as a function of bar corrosion: Part IExperimental test", Materials and structures, 26(8), pp. 453-464 (1993).

15. Suryavanshi, A.K., Swamy, R.N., and Cardew, G.E. "Estimation of diffusion coefficients for chloride ion penetration into structural concrete", Materials Journal, 99(5), pp. 441-449 (2002).

16. Aldea, C.M., Shah, S.P., and Karr, A. "Effect of cracking on water and chloride permeability of concrete", Journal of Materials in Civil Engineering, 11(3), pp. 181-187 (1999).

17. Conciatori, D., Sadouki, H., and Brühwiler, E. "Capillary suction and diffusion model for chloride ingress into concrete", Cement and Concrete Research, 38(12), pp. 1401-1408 (2008).

18. Djerbi, A., Bonnet, S., Khelidj, A., and BaroghelBouny, V. "Influence of traversing crack on chloride diffusion into concrete", Cement and Concrete Research, 38(6), pp. 877-883 (2008).
19. Jang, S.Y., Kim, B.S., and Oh, B.H. "Effect of crack width on chloride diffusion coefficients of concrete by steady-state migration tests", Cement and Concrete Research, 41(1), pp. 9-19 (2011).

20. Wang, L. and Ueda, T. "Mesoscale modelling of the chloride diffusion in cracks and cracked concrete", Journal of Advanced Concrete Technology, 9(3), pp. 241-249 (2011).

21. Marsavina, L., Audenaert, K., De Schutter, G., Faur, N., and Marsavina, D. "Experimental and numerical determination of the chloride penetration in cracked concrete", Construction and Building Materials, 23(1), pp. 264-274 (2009).

22. Kato, E., Kato, Y., and Uomoto, T. "Development of simulation model of chloride ion transportation in cracked concrete", Journal of Advanced Concrete Technology, 3(1), pp. 85-94 (2005).

23. Otieno, M., Beushausen, H., and Alexander, M. "Chloride-induced corrosion of steel in cracked concrete-Part I: Experimental studies under accelerated and natural marine environments", Cement and Concrete Research, 79, pp. 373-385 (2016).

24. Otieno, M., Beushausen, H., and Alexander, M. "Chloride-induced corrosion of steel in cracked concrete-Part II: Corrosion rate prediction models", Cement and Concrete Research, 79, pp. 386-394 (2016).

25. Wang, J., Basheer, P.M., Nanukuttan, S.V., Long, A.E., and Bai, Y. "Influence of service loading and the resulting micro-cracks on chloride resistance of concrete", Construction and Building Materials, 108, pp. 56-66 (2016).

26. Leung, C.K. and Hou, D. "Numerical simulation of chloride-induced corrosion initiation in reinforced concrete structures with cracks", Journal of Materials in Civil Engineering, 27(3), p. 04014122 (2014).

27. Crank, J., The Mathematics of Diffusion, Oxford University Press, Oxford, England (1979).

28. Poulsen, E. and Mejlbro, L., Diffusion of Chloride in Concrete: Theory and Application, CRC Press, Boca Raton, FL, USA (2010).

29. Bentz, D.P., Garboczi, E.J., Lu, Y., Martys, N., Sakulich, A.R., and Weiss, W.J. "Modeling of the influence of transverse cracking on chloride penetration into concrete", Cement and Concrete Composites, $\mathbf{3 8}$, pp. 65-74 (2013).

30. Comsol Multiphysics. See Wikipedia, Bluebook, https://en.wikipedia.org/wiki/COMSOL_Multiphysics (History), "Navier-Stokes equations", Cyclopedia (2016).

31. Jin, W.L., Yan, Y.D., and Wang, H.L. "Chloride diffusion in the cracked concrete", Fracture Mechanics of Concrete and Concrete Structures-Assessment, Durability, Monitoring and Retrofitting of Concrete Structures, pp. 880-886 (2010). 


\section{Biographies}

Mohammad Ghanooni-Bagha received $\mathrm{PhD}$ degree in Structural Engineering at Iran University of Science and Technology in 2015. Now, he is an Assistant Professor in East Tehran Branch, Islamic Azad University, Tehran, Iran. His research interests include durability prediction of concrete structure, reliability analysis, seismic rehabilitation, optimal structural control, wavelet analysis and health monitoring, active and semi-active dampers, and meta-heuristic.

Mohsen Ali Shayanfar received $\mathrm{PhD}$ degree at McGill University in 1995. Now, he is an Associate Professor at Iran University of Science and Technology,
Tehran, Iran. His research interests include nonlinear finite element Method, reliability analysis, durability prediction of concrete structure, seismic rehabilitation, optimal structural control, wavelet analysis and health monitoring, construction management, and meta-heuristic.

Seyed Mohammad Hossein Farnia received MSc degree at Iran University of Science and Technology, in 2016. Now, he is a Research Assistant at the rehabilitation research center in Iran University of Science and Technology, Tehran, Iran. His research interests include durability design of concrete structure, reliability analysis, seismic rehabilitation, wavelet analysis, and health monitoring. 